\title{
CANNABIS USE: PREVALENCE AND CORRELATES AMONG THE INPATIENTS OF FIRST EPISODE PSYCHOSIS AT COMBINED MILITARY HOSPITAL, LAHORE
}

\author{
Mohsin Aliemuddin, Muhammad Kamran*, Zarar Akbar Ch*, Ahmed Shoaib Tabassum**, Farrukh Salim* \\ 70 Medical Battalion Lahore/National University of Medical Sciences (NUMS) Pakistan, ${ }^{*}$ Combined Military Hospital Lahore/National \\ University of Medical Sciences (NUMS) Pakistan, ${ }^{* *}$ Combined Military Hospital Multan/National University of Medical Sciences (NUMS) \\ Pakistan
}

\begin{abstract}
Objective: To determine the frequency and correlates of cannabis use among the psychiatric inpatients presenting with first episode of psychosis at Combined Military Hospital (CMH), Lahore.

Study Design: Correlational study.

Place and Duration of Study: Combined Military Hospital Lahore, from Nov 2016 to Apr 2017.

Methodology: A total of 88 patients between 18-40 years of age, both male and female, meeting the inclusion and exclusion criteria, presenting to Psychiatry department, $\mathrm{CMH}$ Lahore; were enrolled in the study after obtaining their informed consent. Patients were interviewed through Present state examination and the diagnosis was made on the basis of International Classification of Diseases version 10. The data was recorded on the study proforma. Outcome variable was frequency of cannabis abuse among these patients of first episode psychosis. It was compared among various age and gender groups and across educational, marital and residential status of the patient. Results: The mean age of the patients was $26.59 \pm 5.79$ years. There were $57(64.8 \%)$ male and $31(35.2 \%)$ female patients in the study group, with a ratio of 1.8 males to 1 female (1.8:1). Cannabis use was found in 25 (28.4\%) patients. Statistical analysis revealed non-significant difference in the frequency of cannabis use in age $(p=0.15)$, gender $(p=0.69)$, educational $(p=0.91)$, marital $(p=0.180)$ and residential status $(p=0.30)$.

Conclusion: Cannabis use is highly correlated and prevalent among the patients presenting with first episode of psychosis.
\end{abstract}

Keywords: Cannabis use, Psychosis, Substance abuse.

This is an Open Access article distributed under the terms of the Creative Commons Attribution License (http://creativecommons.org/licenses/by/4.0), which permits unrestricted use, distribution, and reproduction in any medium, provided the original work is properly cited.

\section{INTRODUCTION}

Cannabis, also known as marijuana is a preparation of the Cannabis Indica and is used both as a psychoactive drug and medicine. The main psychoactive part of cannabis is tetrahydrocannabinol (THC), it is one of 483 known compounds in the plant ${ }^{1}$. Cannabis is the most popular illicit drug in the world and its prevalence in Pakistan is about $4.0 \%$. The 2013 National Survey on Drug Use reported that more than 4 million people in Pakistan use cannabis on a regular basis, most of whom started using cannabis and other drugs during their teenage years ${ }^{2}$. International Mental health surveys have repeatedly found more substance use, especially cannabis use, among people with a diagnosis of a psychotic disorder 3,4 . Pros-

Correspondence: Dr Muhammad Kamran, Dept of Psychiatry, Combined Military Hospital Malir Pakistan

Received: 01 Mar 2019; revised received: 01 Aug 2019; accepted: 07 Aug 2019 pective epidemiological studies have consistently reported that use of cannabis in younger age group increases the risk of schizophrenia-like psychosis; onset age of psychosis is reduced, as well5,6. A popular idea suggested that immature brain might be the reason behind increased susceptibility to adverse effects of cannabis 7 .

Co-occurring substance use disorders, mostly involving alcohol, cannabis or cocaine, occur commonly in patients with schizophrenia and are associated with increased morbidity and mortality $^{8}$. Data suggests that substance use disorders (especially cannabis use disorders) may also be common in first-episode psychotic patients and appears to be linked to a poor outcome in these patients.

According to a study conducted in USA, 37\% patients of first episode psychosis had a lifetime diagnosis of substance use disorder (SUD). $28 \%$ 
out of these had a lifetime cannabis use disorder (CUD) and $21 \%$ had a lifetime diagnosis of alcohol use disorder (AUD). Patients with SUD were more likely to be men. Those with CUD had a lower age of onset than those without ${ }^{9}$. Another study conducted in Spain found co-morbid cannabis use of $29 \%$ in children and adolescents with first episode psychosis ${ }^{10}$. However, limited data is available showing the cannabis use frequency in the patients with first episode psychosis in any mental health facility of Pakistan.

This study will highlight this neglected behavioural problem responsible for excess morbidity and mortality in this vulnerable subgroup of population so that strategies can be devised to help them at clinical as well as institutional/ hospital levels. Cases of psychotic disorder could also be prevented by discouraging cannabis use among vulnerable youths.

\section{METHODOLOGY}

This correlational study was conducted in Psychiatry ward, Combined Military Hospital, Lahore from November 2016 to April 2017. Sample size $(n=88)$ was calculated by using the WHO sample size calculator ${ }^{11}$, including parameters: 95\% Confidence Level, 35\% Population proportion $^{12}$ and Precision to be $10 \%$.

Study was approved from the ethics committee of CMH Lahore (Approval Certificate No.60 /2017). A total of 88 patients between 18-40 years of age, both male and female, who had first episode psychosis meeting the ICD-10 diagnostic criteria were enrolled. They were admitted in Psychiatry ward, CMH Lahore during the study period. Enrollment was carried out through Consecutive non-probability sampling, after obtaining informed consent. Data was collected with the help of detailed questionnaire. Patients having history of any previous treatment for psychosis or evidence of psychotic symptoms precipitated by an organic cause were excluded for current study. Presence of psychosis was confirmed by using Present state examination Urdu version and International Classification of Diseases (ICD) version 10. Cannabis use was confirmed by labo- ratory investigation of urine for THC (Tetrahydrocannabinol). Data was analyzed through SPSS version 21. Numerical variables like age have been presented by mean \pm SD. Categorical variables like gender, cannabis use status, education, marital status and residence have been presented as frequency and percentage. Post-stratification Fishers exact test has been applied taking $p \leq 0.05$ as significant.

\section{RESULTS}

Total 88 patients with the age ranged from 18 years to 40 years were included in the study; with a mean age of $26.6 \pm 5.8$ years. Based on the age, study participants were divided into different age groups. Cannabis users among different age groups along with the percentages are given in figure. There were 57 (64.8\%) male and 31 (35.2\%) female patients, with a ratio of 1.8 males to 1 fe-

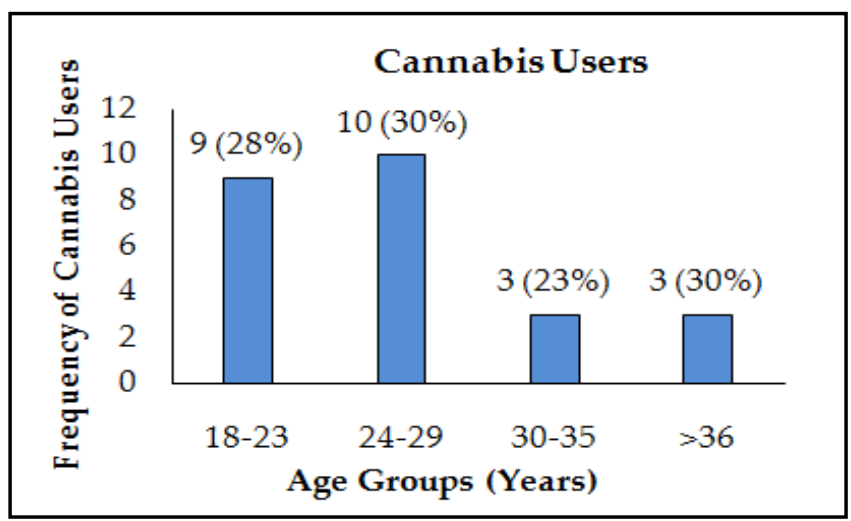

Figure: Frequency of cannabis users among different age groups.

male (1.8:1). It was found that $56(63.6 \%)$ patients belonged to rural whereas $32(36.4 \%)$ patients were from urban/city areas. Majority 47 (53.4\%) of the patients were un-married and divorced / widowed were $11(12.5 \%)$ patients. It was found that $31(35.2 \%)$ patients were matriculate while only $14(15.9 \%)$ patients had a graduate degree. Cannabis use was found in $25(28.4 \%)$ patients. Statistically non-significant association $(p=0.15)$ was found for age and cannabis use. Moreover, upon stratification no association $(p=0.96)$ was found even between different age groups and cannabis use. Cannabis use was reported to be independent of gender with a non-significant asso- 
ciation $(p=0.689)$. No association was found for educational $(p=0.9)$ and marital status $(p=0.18)$. It was found that cannabis use was common in both urban and rural areas with non-significant $(p=$ $0.30)$ results, as given in table. mean age of $25.44 \pm 6.32$ years among British patients presenting with First-Episode Psychosis ${ }^{18}$ while relatively higher mean age of $32 \pm 7.8$ years has been reported by Naeem et al 2016 among such patients presenting at Sir Ganga Ram Hospital at Lahore ${ }^{19}$.

Table: Association of various effect modifiers with cannabis use.

\begin{tabular}{|c|c|c|c|c|c|}
\hline \multirow{2}{*}{\multicolumn{2}{|c|}{ Variables }} & \multicolumn{3}{|c|}{ Cannabis Use } & \multirow{2}{*}{$p$-value } \\
\hline & & Yes & No & $\%$ & \\
\hline \multirow{2}{*}{ Gender } & Male $(\mathrm{n}=57)$ & 17 & 40 & 29.82 & \multirow{2}{*}{0.689} \\
\hline & Female $(\mathrm{n}=31)$ & 08 & 23 & 25.80 & \\
\hline \multirow{4}{*}{ Educational status } & Illiterate $(\mathrm{n}=25)$ & 08 & 17 & 32 & \multirow{4}{*}{0.91} \\
\hline & Matriculate $(\mathrm{n}=31)$ & 09 & 22 & 29 & \\
\hline & Intermediate $(\mathrm{n}=18)$ & 05 & 13 & 27.78 & \\
\hline & Graduate $(n=14)$ & 03 & 11 & 21.4 & \\
\hline \multirow{3}{*}{ Marital status } & Married $(n=47)$ & 17 & 30 & 36.17 & \multirow{3}{*}{0.18} \\
\hline & Unmarried $(\mathrm{n}=30)$ & 05 & 25 & 16.67 & \\
\hline & Divorced/Widowed $(\mathrm{n}=11)$ & 03 & 08 & 27.27 & \\
\hline \multirow{2}{*}{ Residential status } & Rural $(n=56)$ & 18 & 38 & 32.14 & \multirow{2}{*}{0.304} \\
\hline & Urban $(n=32)$ & 07 & 25 & 21.87 & \\
\hline
\end{tabular}

\section{DISCUSSION}

Co-occurring substance use disorders, mostly involving alcohol, cannabis or cocaine occur commonly in patients with schizophrenia ${ }^{13,14}$. Prospective epidemiological studies have consistently reported that use of cannabis in younger age group increases the risk of schizophrenia like psychosis and that the age of onset is also reduced $^{14}$. The limited available data also suggests that substance use disorders (especially cannabis use disorders) may also be common in firstepisode psychotic patients and appear to be associated with poor outcome in these patients ${ }^{15}$. The available evidence on frequency of cannabis use in patients with first episode of psychosis varied among various studies in different populations ${ }^{5,9,13-15}$.

In the present study, the mean age of the patients was $26.59 \pm 5.79$ years. Naqvi et al 2010 reported similar mean age of $24.86 \pm 8.83$ years among patients presenting with psychosis at The Aga Khan University Hospital, Karachi ${ }^{16}$. A similar mean age of $28 \pm 8.32$ years has been reported by Bianconi et al 2015 among British such patient ${ }^{17}$. Schoeler et al 2016 also reported similar
There were 57 (64.8\%) male and 31 (35.2\%) female patients in the study group with a male to female ratio of 1.8:1. A similar male predominance among patients with psychosis has also been observed by Bukhsh et al ${ }^{20}(2.3: 1)$, Naqvi et al16 (1.4:1) and Naeem et al ${ }^{19}$ (1.2:1) in Pakistan. Baeza et al reported similar male predominance with a male to female ratio of 1.9:1 among Spanish such patients ${ }^{10}$. Bhui et al also reported similar male predominance with a male to female ratio of 1.6:1 in British such patients ${ }^{21}$. A similar male predominance (m:f, 2.7:1) among Australian such patients was reported by Hides et al22 Skinner et al however observed a female predominance and reported a male to female ratio of 1:4.6 among Irish such patients ${ }^{23}$.

Majority $(53.4 \%)$ of the patients were unmarried followed by married (34.1\%) and divorced/ widowed (12.5\%) patients. A similar frequency of un-married (49.2\%), married (37.2\%) and divorced/widowed patients $(13.6 \%)$ was reported previously by Naqvi et al among such patients presenting at The Agha Khan University Hospital, Karachi ${ }^{16}$. 
Cannabis use was found in $25(28.4 \%)$ patients. Our observation is similar to that of Green $e t$ al who reported this frequency to be $28 \%$ among American patients with first-episode psychosis ${ }^{9}$. A similar frequency of $29.9 \%$ was reported by Verdoux et al in France ${ }^{24}$ while Schoeler observed it to be $31.36 \%$ in England ${ }^{18}$. Skinner et al however observed relatively higher frequency of $40 \%$ in Irish such patients ${ }^{23}$. A much higher frequency of $51.85 \%$ and $70.4 \%$ has been reported by Mulè et al and Hides et al in British and Australian such patients respectively 22,25 .

The present study is first of its kind in local population and has found the frequency of cannabis use to be $28.4 \%$ among patients presenting with first episode of psychosis irrespective of patient's age and gender and educational, marital and residential status. In the light of results of the present study it can be advocated that in future practice patients presenting with first-episode psychosis should be screened for cannabis use. There is also need for community measures to reduce cannabis usage. We observed higher frequency of cannabis use among young, males who were illiterate and un-married or divorced/ widowed. We also observed higher frequency of cannabis use in patients coming from rural areas. Though insignificant these differences still mean a lot and necessitate community measures targeting this population.

The strengths of the present study were strict exclusion criteria and stratification of study results for effect modifiers. A strong limitation however was limited sample size of 88 cases. Moreover, it was a single center study and the results of the present study cannot be generalized to whole population. There is need for a multicenter larger study to further establish the magnitude of problem. Such a study is highly recommended in future research.

\section{CONCLUSION}

Cannabis use is highly correlated and prevalent among the patients presenting with first episode of psychosis. However, it was not correlated to patient's age or gender; neither do to his/her educational, marital and residential status.

\section{CONFLICT OF INTEREST}

There is no conflict of interest to be declares by any author.

\section{REFERENCES}

1. Murray RM, Quigley H, Quattrone D, Englund A, Di Forti M. Traditional marijuana, high.potency cannabis and synthetic cannabinoids: increasing risk for psychosis. World Psychiatr 2016; 15(3): 195-204.

2. Batool S, Manzoor I, Hassnain S, Bajwa A, Abbas M, Mahmood $\mathrm{M}$, et al. Pattern of addiction and its relapse among habitual drug abusers in Lahore, Pakistan. East Mediterr Health J 2017; 23(3): 83-89.

3. Di Forti M, Marconi A, Carra E, Fraietta S, Trotta A, Bonomo M, et al. Proportion of patients in south London with first-episode psychosis attributable to use of high potency cannabis: a casecontrol study. Lancet Psychiatr 2015; 2(3): 233-38.

4. Marconi A, Di Forti M, Lewis CM, Murray RM, Vassos E. Metaanalysis of the association between the level of cannabis use and risk of psychosis. Schizophr Bull 2016; 42(5): 1262-69.

5. Donoghue K, Doody GA, Murray RM, Jones PB, Morgan C, Dazzan $P$, et al. Cannabis use, gender and age of onset of schizophrenia: data from the AESOP study. Psychiatry Res 2014; 215(3): 528-32.

6. Gage SH, Hickman M, Zammit S. Association between cannabis and psychosis: epidemiologic evidence. Biol Psychiatry 2016; 79(7): 549-56.

7. Edalati H, Doucet C, Conrod PJ. A developmental social neuroscience model for understanding pathways to substance use disorders during adolescence. Semin Pediatr Neurol 2018; 10(2): 345-57.

8. Singh S, Balhara YPS. A review of indian research on cooccurring psychiatric disorders and alcohol use disorders. Indian J Psychol Med 2016; 38(1): 10-19.

9. Green AI, Tohen MF, Hamer RM, Strakowski SM, Lieberman JA, Glick I, et al. First episode schizophrenia-related psychosis and substance use disorders: acute response to olanzapine and haloperidol. Schizophrenia Res 2004; 66(2): 125-35.

10. Baeza I, Graell M, Moreno D, Castro-Fornieles J, Parellada M, González-Pinto A, et al. Cannabis use in children and adolescents with first episode psychosis: Influence on psychopathology and short-term outcome (CAFEPS study). Schizophrenia Res 2009; 113(2): 129-37.

11. Pourhoseingholi MA, Vahedi M, Rahimzadeh M. Sample size calculation in medical studies. Gastroenterology and hepatology from bed to bench. Winter 2013; 6(1): 14-17.

12. Burns J, Jhazbhay K, Emsley R. Cannabis use predicts shorter duration of untreated psychosis and lower levels of negative symptoms in first-episode psychosis: a South African study. S Afr J Psychol 2010; 13(5): 145-60.

13. Iqbal MN, Levin CJ, Levin FR. Treatment for substance use disorder with co-occurring mental illness. Focus Am Psychiatr Publ 2019; 17(2): 88-97.

14. Khokhar JY, Dwiel LL, Henricks AM, Doucette WT, Green AI. The link between schizophrenia and substance use disorder: A unifying hypothesis. Schizophrenia Res 2018; 21(7): 78-85.

15. Volkow ND, Swanson JM, Evins AE, DeLisi LE, Meier MH, Gonzalez R, et al. Effects of cannabis use on human behavior, including cognition, motivation, and psychosis: a revieweffects 
of cannabis use on human behavior effects of cannabis use on human behavior. J Am Med Assoc Psychiatry 2016; 73(3): 292-97.

16. Naqvi I, Murtaza M, Nazir MR, Naqvi HA. Gender difference in age at onset of schizophrenia: A cross sectional study from Pakistan. J Pak Med Assoc 2010; 60(10): 886-90.

17. Bianconi F, Bonomo M, Marconi A, Kolliakou A, Stilo SA, Iyegbe $C$, et al. Differences in cannabis-related experiences between patients with a first episode of psychosis and controls. Psychol Med 2015; 46(5): 995-1003.

18. Schoeler T, Petros N, Di Forti M, Pingault JB, Klamerus E, Foglia $\mathrm{E}$, et al. Association between continued cannabis use and risk of relapse in first-episode psychosis: a quasi-experimental investigation within an observational study. J Am Med Assoc psychiatr 2016; 73(11): 1173-79.

19. Naeem F, Habib N, Gul M, Khalid M, Saeed S, Farooq S, et al. A qualitative study to explore patients', carers' and health professionals' views to culturally adapt CBT for psychosis (CBTp) in Pakistan. Behav Cogn Psychother 2016; 44(1): 43-55.

20. Bukhsh A, Ali Z, Tayyab M, Gohar Z, Amjad S. Comparative
Evaluation of Side Effects of Typical and Atypical Antipsychotics in Psychotic Patients at Punjab Institute of Mental Health, Lahore, Pakistan. Bipolar Disorder 2014; 15(4): 25-29.

21. Bhui K, Ullrich S, Kallis C, Coid JW. Criminal justice pathways to psychiatric care for psychosis. Br J Psychiatry 2015; 207(6): 523-29.

22. Hides L, Dawe S, Kavanagh D, Young RM. Psychotic symptom and cannabis relapse in recent-onset psychosis: prospective study. Br J Psychiatry 2006; 189(2): 137-43.

23. Skinner R, Conlon L, Gibbons D, McDonald C. Cannabis use and non-clinical dimensions of psychosis in university students presenting to primary care. Acta Psychiatrica Scandinavica 2011; 123(1): 21-27.

24. Verdoux H, Sorbara F, Gindre C, Swendsen JD, van Os J. Cannabis use and dimensions of psychosis in a nonclinical population of female subjects. Schizophrenia Res 2003; 59(1): 7784.

25. Mulè A, Sideli L, Colli G, Ferraro L, Cascia LAC, Sartorio C, et al. Cannabis consumption and the risk of psychosis. Evidencebased Psychiatric Care 2017; 3(1): 25-31. 